\title{
Bariatric Surgical Simulation: Evaluation in a Pilot Study of SimLife, a New Dynamic Simulated Body Model
}

\author{
J. Danion ${ }^{1,2} \cdot$ G. Donatini ${ }^{1,2} \cdot$ C. Breque ${ }^{1} \cdot$ D. Oriot $^{1} \cdot$ J. P. Richer ${ }^{1,2} \cdot$ J. P. Faure ${ }^{1,2}$ (I)
}

Received: 21 April 2020 / Revised: 25 June 2020 / Accepted: 25 June 2020 / Published online: 3 July 2020

(C) Springer Science+Business Media, LLC, part of Springer Nature 2020

\begin{abstract}
Background The demand for bariatric surgery is high and so is the need for training future bariatric surgeons. Bariatric surgery, as a technically demanding surgery, imposes a learning curve that may initially induce higher morbidity. In order to limit the clinical impact of this learning curve, a simulation preclinical training can be offered. The aim of the work was to assess the realism of a new cadaveric model for simulated bariatric surgery (sleeve and Roux in Y gastric bypass).

Aim A face validation study of SimLife, a new dynamic cadaveric model of simulated body for acquiring operative skills by simulation. The objectives of this study are first of all to measure the realism of this model, the satisfaction of learners, and finally the ability of this model to facilitate a learning process.

Methods SimLife technology is based on a fresh body (frozen/thawed) given to science associated to a patented technical module, which can provide pulsatile vascularization with simulated blood heated to $37^{\circ} \mathrm{C}$ and ventilation.

Results Twenty-four residents and chief residents from 3 French University Digestive Surgery Departments were enrolled in this study. Based on their evaluation, the overall satisfaction of the cadaveric model was rated as 8.52 , realism as 8.91 , anatomic correspondence as 8.64 , and the model's ability to be learning tool as 8.78 .

Conclusion The use of the SimLife model allows proposing a very realistic surgical simulation model to realistically train and objectively evaluate the performance of young surgeons.
\end{abstract}

Keywords Bariatric surgery $\cdot$ Learning curve $\cdot$ Surgical simulation $\cdot$ SimLife

\section{Introduction}

As obesity has become a worldwide public health concern, bariatric surgery has been also recognized as an appropriate and effective method to treat obesity and its related diseases [1-5]. The training needs for bariatric surgeons are therefore increasing in order to maintain a high quality of care for obese patients.

\author{
J. P. Faure \\ jean.pierre.faure@univ-poitiers.fr; j.p.faure@chu-poitiers.fr \\ J. Danion \\ jerome.danion@chu-poitiers.fr \\ G. Donatini \\ gianluca.donatini@chu-poitiers.fr \\ C. Breque \\ cyril.breque@univ-poitiers.fr
}

As reported in the literature [5], 3 major factors influence bariatric surgery care: hospital infrastructure and volume, surgical team volume, and surgical skills. While it may be difficult to change the first 2 factors that are not dependent on the surgeon, the third can be improved.

Surgical simulation provides the opportunity for supervised directed learning of trainees, allowing full mastering of technical skill and increasing performances before actual practice on patients [6-9].

D. Oriot

denis.oriot@univ-poitiers.fr

J. P. Richer

jean.pierre.richer@univ-poitiers.fr

1 ABS LAB, University Medical School of Poitiers, rue de la Milétrie, Bâtiment D1, TSA 5111586073 Poitiers Cedex France

2 Departemant of Visceral, Digestif and Endocrine Surgery, University Hospital of Poitiers, 2 rue de la Miletrie BP 57786021 Poitiers Cedex France 
For this purpose, we developed the SimLife model, based on fresh human body given to science, dynamized by pulsatile vascularization with simulated blood, warmed to $37^{\circ} \mathrm{C}$ and ventilation $[10,11]$.

The objectives of this study were to assess the realism of this model, the satisfaction of learners, and finally the ability of this model to facilitate the learning process.

\section{Method}

The SimLife model consists of a donated human body, which is retrieved by the Body Donation Center of our university, prepared for surgical simulation [10]. Bodies arrived within $24 \mathrm{~h}$ after death, and a traceability number (anonymity) is established [10-12].

Exclusion criteria included all possible contaminations such as HIV, HBV, HCV, Creutzfeldt-Jacob, and tuberculosis, through analysis of a blood sample to perform serological tests; at the time of those simulations (2019) we were unaware of the risk of Coronavirus infection, but now we systematicaly tested all cadavers about the COVID status at their arrival at the Body Donation Center.

Each body was then prepared for surgical simulation (Fig. 1): cannulas were placed in both femoral arteries and left common carotid artery (input) and both femoral veins and left internal jugular veins (output). The vascular axes of superior and inferior limbs may be excluded to target the trunk's vascularization [10-12]. A tracheotomy or orotracheal tube provided ventilation, and stomach emptying was obtained via a nasogastric tube.

Body's arterial tree was washed with water at low pressure ( 0.8 bar) and at a maximum temperature of $30^{\circ} \mathrm{C}$ to eliminate whole blood and clots. Subsequent body cleaning and disinfection was performed and the body was frozen at $-22^{\circ} \mathrm{C}$ in a negative pressure cold room $[7,8]$.

When a SimLife simulation session was scheduled, before use and according to bodies' BMI, progressive body defrosting (at $16^{\circ} \mathrm{C}$ ) over several days (3 days minimum) was achieved. Finally, a testing procedure before starting on SimLife model was performed to check the physiological behavior of the model.

The specific technical module P4P (Pulse For Practice, patent number 1000318748 with international extension PCT/EP2016/075819 published on 2017/05/11, WO 2017/ 076717 A1) animated the body, which was perfused by blood-mimicking fluid (patent L18217) circulating in the arterial system in a pulsating manner, recoloring and warming internal organs to $37^{\circ} \mathrm{C}$, and restoring venous turgor. Output was guaranteed by venous output. Physiological
Fig. 1 Schema of global vascular and aeric accesses of SimLife and the connections with the specific Pulse for Practice ${ }^{\circledR}$ device dedicated to re-vascularization and re-ventilation in a model of abdomino-pelvic and thoracic surgery

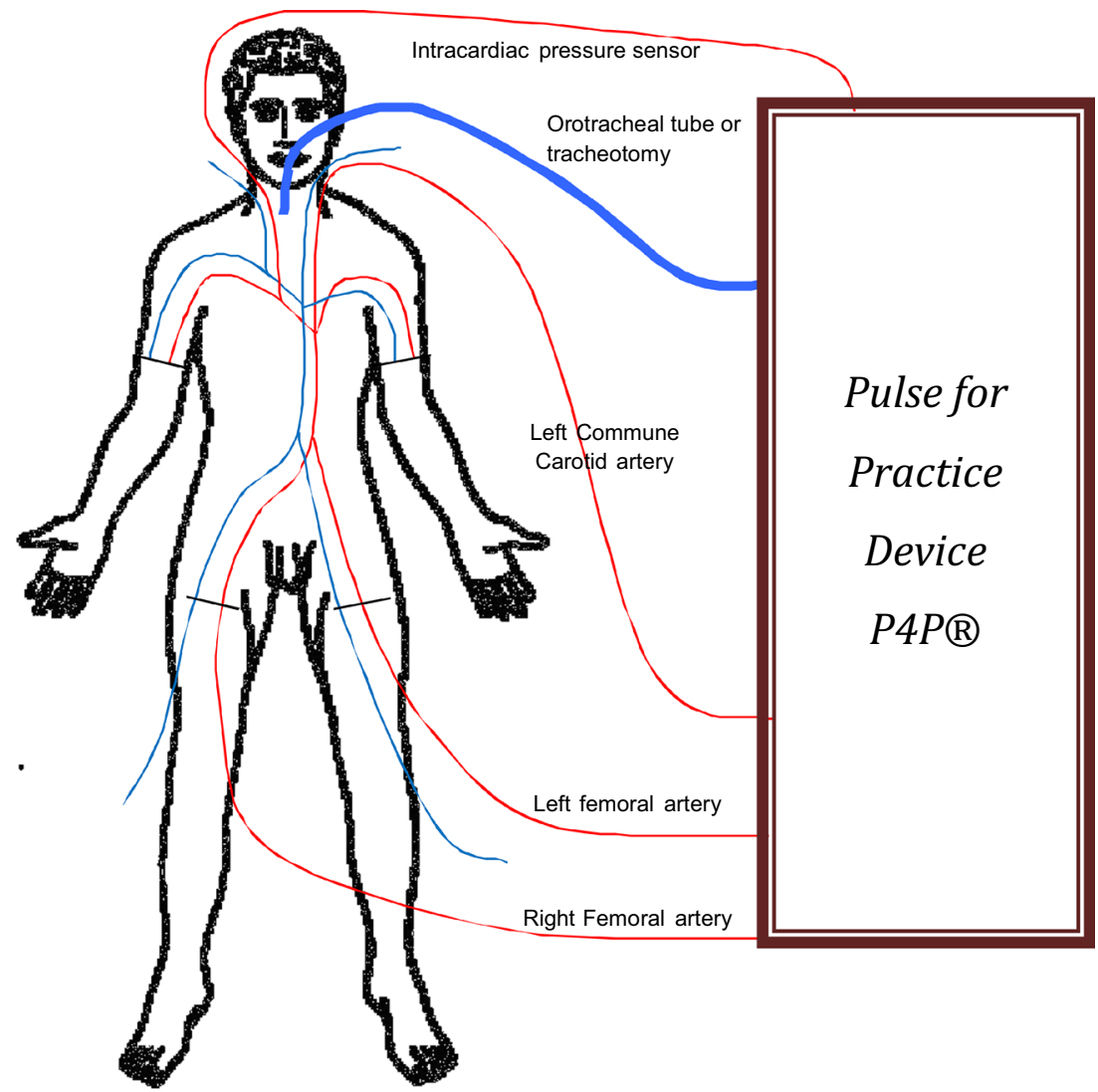


hemodynamic data were computer monitored continuously and adapted as needed, with heart rate, blood pressure, and respiratory rate, which could increase or decreased to mimic a hemorrhagic shock for example.

SimLife inner organs were re-vascularized, re-colored, and warmed by specific mimicking-blood liquid. Hemodynamic conditions were maintained and could be continuously modified by a computer-controlled device, ensuring identical physiological conditions of a real patient. For example, the pulsatile pump controlled by the computer automatically adjusted blood pressure according to possible iatrogenic accidents causing bleeding. Thus, a moderate bleeding induced an increase in flow up to a threshold where hemodynamic instability resulted in a complete loss of blood pressure and systemic circulation interruption [10-12].

The learning platform on cadaveric model was covered by previous approval of French Ministry of Health Ethics Committee (protocol number DC-2019-3704).

\section{Study Design and Participants}

A total of 24 residents and chief residents (Table 1) consented to this study on a total of 4 occasions. The training days were hosted at the Medical school. Before performing each procedure, all participants were given a theoretical approach, which included lectures, videos, description of the technique, and an overview to the reperfused cadaver model. This was followed by hand-on training on SimLife models. We associated 2 trainees per station, with at least 1 supervising expert.

The theme of the first 2 sessions was the sleeve gastrectomy, and the 2 following sessions were the Roux-in-Y gastric bypass; this sequence allowed trainees to familiarize themselves with the SimLife model for a relatively simple procedure and then to move to a more technically demanding gastric by-pass.

Table 1 Numbers, status of trainees, and their previous experience in bariatric surgery

\begin{tabular}{|c|c|c|c|}
\hline Status & $\mathrm{Nu}$ & mber & Mean and SD \\
\hline \multirow[t]{3}{*}{ Residents } & \multirow[t]{3}{*}{20} & Number of bariatric procedure achieved & $0.88(1.87)$ \\
\hline & & $\begin{array}{l}\text { Number of bariatric procedure as } \\
\text { assistant }\end{array}$ & $9.82(5.91)$ \\
\hline & & Number of bariatric procedure observed & $15.84(9.81)$ \\
\hline \multirow{3}{*}{$\begin{array}{l}\text { Chief } \\
\text { residents }\end{array}$} & \multirow[t]{3}{*}{4} & Number of bariatric procedure achieved & $7.83(5.83)$ \\
\hline & & $\begin{array}{l}\text { Number of bariatric procedure as } \\
\text { assistant }\end{array}$ & $30.83(8.79)$ \\
\hline & & Number of bariatric procedure observed & $50.94(9.78)$ \\
\hline \multirow[t]{3}{*}{ Total } & \multirow[t]{3}{*}{24} & Number of bariatric procedure achieved & $3.14(5.97)$ \\
\hline & & $\begin{array}{l}\text { Number of bariatric procedure as } \\
\text { assistant }\end{array}$ & $9.29(7.82)$ \\
\hline & & Number of bariatric procedure observed & $12.15(10.72)$ \\
\hline
\end{tabular}

\section{Evaluation Survey}

At the end of each practical session, all surgical trainees completed an anonymous evaluation survey indicating their degree of satisfaction (feedback) on a Likert scale from 0 to 10 $(0=$ not at all to $10=$ perfectly $)$ on 4 items:

1. Ease of learning a specific surgical procedure using SimLife model,

2. Accuracy of anatomic landmarks of SimLife model compared with clinical reality,

3. Degree of realism of SimLife model,

4. Overall satisfaction with the training model used.

\section{Statistical Analysis}

Statistical analysis was performed by means of SAS 9.3 software. Values are reported as means and standard deviation (SD). Results are summarized in Table 1.

\section{Results}

All participants completed and returned the evaluation survey corresponding to a response rate of $100 \%$ from the trainees. Participants included 20 residents and 4 chief residents from the French Nouvelle Aquitaine area including three university hospitals: Bordeaux, Limoges, and Poitiers. Their status and experience in bariatric surgery are summarized on Table 2.

The evaluation survey was carried out at the end of each session. Data were collected from the 4 training sessions. The 24 participants answered to the four survey questions. Based on these evaluations, the overall satisfaction of the cadaveric model had a mean score of 8.52 with SD of 0.83 , realism had a mean score of 8.91 with SD of 0.94 , anatomic correspondence had a mean score of 8.64 with SD of 0.96 , and the model's ability to be learning tool had a mean score of 8.78 with SD of 0.85 (Table 2).

On the evaluation form given to each trainee the final question was as follows: would you advise a colleague to

Table 2 Trainees' responses to questionnaire (on a 0-10 Likert scale) about the quality of the model

\begin{tabular}{ll}
\hline Questions & $N=24$ \\
\hline Learning a procedure with this model & $8.78(0.85)$ \\
Anatomic correspondence & $8.64(0.96)$ \\
Realism & $8.91(0.94)$ \\
Overall satisfaction & $8.52(0.83)$ \\
\hline
\end{tabular}


participate in a training course using the SimLife model? One hundred percent of the trainees answered yes.

\section{Discussion}

Bariatric surgery requires, as well as other surgical subspecialties, acquisition of specific skills, which may be learnt throughout consistent practice. Corresponding at the Halstedian model of apprenticeship "learning on the job" creates the notion of a learning curve. The relationship between hospital volume and outcomes is well recognized; at least 100 cases annually per hospital are recommended as the minimal requirement to achieve a low risk for serious complications [13]. Moreover, a total experience of 500 cases was deemed necessary to diminish the risk for adverse outcomes and meet safety standards [13].

But an individual case report of 100 cases annually is not always feasible, and we focused on revisional bariatric surgery, as cited by Bonrath; in Germany an individual case volume of 300 procedures is referenced as a quality criterion [5].

The paradigm shift of training in surgery In experimental learning, Kolb showed that strategy of the initial used in learning process influences adequate skill acquisition [14]. Concerning bariatric surgery, the value of the classical surgical cursus, residency and fellowship training, is well documented [5, 9, 15-18]. But availability of fellowship in a high debit department of bariatric surgery is not the rule for all young surgeons. In Germany, as reported by Bonrath, over $80 \%$ of surgeons had none or little exposure to fellowship training [5]. While in North America a "Fellowship trained" is the rule to independently perform bariatric surgery. So designing fellowship training induced debate within the bariatric surgery societies without finding a worldwide agreement because the means available and the modalities of evaluation vary greatly from one country to another and sometimes from one university to another [8, 19-21].

Other solutions have been proposed, for example, the SAGES telementoring, which allows surgeons to reach the plateau of maximum performance more quickly by "correcting" intraoperative gestures, thanks to experts who can follow the procedure remotely. An evaluation is proposed via this device; unfortunately, it is only subjective since it is left to the expert's free appreciation [22] and always on a patient.

So in the last two decade, the surgical community stated that mentorship should not be the method of instruction that best prepares trainees to enter the modern world of surgery $[6$, $8,17-21]$. The milestone of the "new concept of training" should consist in exposing apprentices to features of real-life situations, without risks for living patients.

Surgical trainees may also benefit by activities performed far from operating theaters such as surgical simulation
[23-25], coaching [26, 27], structured training programs [28], and many others [13].

In fact, the learning curve must shift from the operating theater to a "preclinical" model in simulation. This "natural" evolution of training also follows the incredible technological progress of surgery where the practitioner must master not only his surgical technique but also the tool he uses.

Which model for surgical simulation and evaluation?

Donald Kirkpatrick [29] in the late 1950s defined a training evaluation model based on four levels of evaluation. Each level is built from the information of the previous levels. In other words, a higher level is a finer and more rigorous assessment of the previous level: Level 1: Assessment of reactions, Level 2: Learning assessment, Level 3: Evaluation of transfer, and Level 4: Outcome Evaluation.

Level 1 with assessment of learners' reactions in front of the simulation model is fundamental. If we try to compare the simulation training of pilots and surgeons: a crucial element emerges. While computer models can perfectly simulate a long-distance flight with all possible anomalies, the same cannot be said for computerized surgical simulation. The root of surgical simulation should be the realism of the model to obtain the most immersive environment to the learners [30, 31].

A wide number of surgical simulators are available for the benefit of trainees $[6,7,9,10,30,32-41]$. They can be divided into synthetic and organic simulators [7,9]. Within the first group we have plastic, rubber, or latex-based simulator as well as virtual reality (VR) and computer-based simulation. Those simulators have the advantage to allow repetition of practice without any risk (no living being used), but these tools may sometimes present a lack of reality compared with human patients [7]. It is necessary to adapt simulation models to anatomical and/or physiological variations that cannot be perfectly programmed in a computerized scenario [42-44].

Organic type simulators provide high-fidelity environment and may be divided into animal-based and human-based. The first type is mainly represented by canine, baboons, or porcine model [7]. Nevertheless, some ethical restriction applied as living animal models are forbid in the UK and open discussion exist in some other European countries [7, 44].

The second organic model is represented by human cadaver, the historical model for practical training in surgery or interventional medicine [45, 46]. Indeed, fresh or embalmed human cadavers have been used for centuries as a learning tool in clinical anatomy $[33,34]$. The major pitfall of human corpse is represented by the fact that this is a static model, which could not simulate actual condition of surgery like bleeding and hemodynamic instability, one of the most critical conditions that a surgeon may face, especially during laparoscopy [35-38].

To overcome this problem few teams introduced model of perfused cadaveric material, mainly in neurosurgery, reporting higher satisfaction of trainees and increased fidelity, similar to a living patient [6, 40-42]. These late reports 


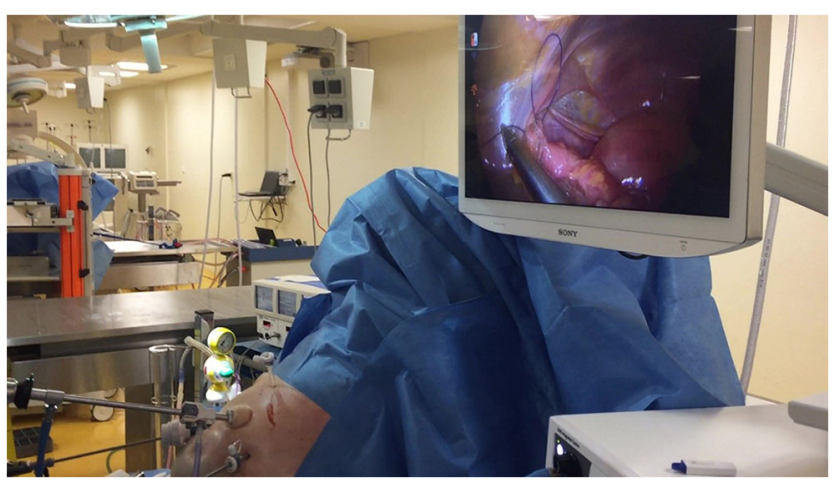

Fig. 2 Global view of laparoscopic sleeve gastrectomy during a bariatric SimLife session

particularly highlight the increased degree of reality represented by a perfused cadaveric model, which allowed training in hyper-realistic environment [39-41].

Furthermore, the use of cadavers is also a source of ethical reflection and emotional and psychological analysis for learners in their surgical behavioral training $[47,48]$.

Training on a cadaveric model (Figs. 2 and 3 ) seems to be the best compromise between learning in the operating room, the animal model, and/or virtual simulators [35].

Surgical apprenticeship on SimLife is performed safely and achieved a high satisfaction score among trainees, as shown previously. This last point is truly important as apprentice appreciation of simulators is the key to provide successful training as it allows gaining of confidence, increasing of experience, and mastering of surgical techniques, which may be lately translated into proficient medical practice $[29,41]$.

\section{Limitations of SimLife Model}

First, the SimLife model revascularization by a bloodmimicking fluid-limited coagulation, platelet activation, and

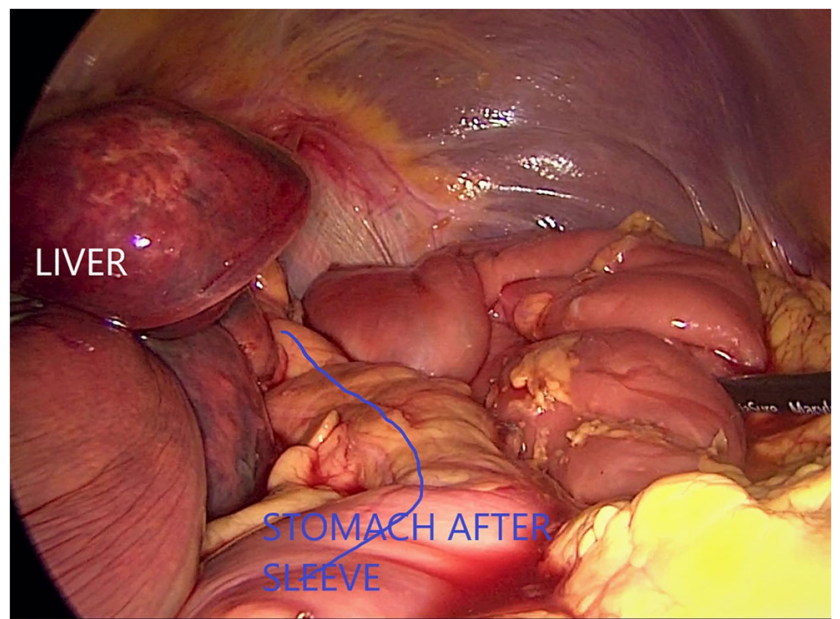

Fig. 3 Intraopertive view after a slleve gastrectomy: the stomach after sleeve gastrectomy thrombin-derived products could not be achieved as in a real standard patient. So the environment is closer to an extracorporeal circulation model.

Second, body availability and moreover overall mean cost per procedure limited the access to this model. This simulations' device cannot be reserved as initial training for junior residents, but it has to be implemented at the end of basic skills learning, which may be achieved on simpler models. Thus, SimLife should ideally be used for training in the last period of residency or during fellowship program to ensure skills mastering just before practicing on clinical theater. To also limit the cost, it is possible to set up SimLife training sessions with several specialties: on day one, orthopedic surgery; on day 2 , bariatric and/or endocrine surgery (thyroidectomy with lymph node dissection for example, in this case it is necessary to adapt the body preparation without neck dissection: cannulas placement can be modified as required); and on day 3, cardiac surgery (heart valve surgery). To look further, this model can be implemented in other universities and countries.

\section{Conclusion}

SimLife introduced a realistic bariatric surgery simulation model. It represents a relevant tool that can have a positive impact on the acquisition and mastery of advanced technical skills for young surgeons. The next step in this work will be the evaluation of performance acquisition over several sessions using specific evaluation scales.

\section{Compliance with Ethical Standards}

Conflict of Interest C Breque, D Oriot, JP Richer, and JP Faure are patent co-owner of the $\mathrm{P} 4 \mathrm{P}$ device permitting revascularization and reventilation.

All other authors declare that they have no conflict of interest.

Statement of Human Rights The learning platform on cadaveric model is covered by previous approval of French Ministry of Health Ethics Committee (protocol number DC-2019-3704).

Informed Assent and Consent Informed consent was obtained from all individual participants included in the study.

\section{References}

1. Hales C, Carroll M, Fryar C, et al. Prevalence of obesity among adults and youth: United States, 2015-2016. NCHS Data Brief. 2017;288

2. World Health Organization. Obesity and overweight. 2017 [cited 2018 21.06.2018]; Available from: http://www.who.int/newsroom/fact-sheets/detail/obesity-and-overweight.

3. Borisenko O, Colpan Z, Dillemans B, et al. Clinical indications, utilization, and funding of bariatric surgery in Europe. Obes Surg. 2015;25:1408-16. 
4. ASMBS. Estimates of bariatric surgery numbers, 2011-2016. [21.06.2018]; Available from: https://asmbs.org/resources/ estimate-of-bariatric-surgery-numbers.

5. Bonrath EM, Weiner S, Birk D, et al. Training in bariatric surgery: a national survey of German bariatric surgeons. Obes Surg. 2020;30(1):56-62. https://doi.org/10.1007/s1 1695-019-04137-3.

6. Tan SS, Sarker SK. Simulation in surgery: a review. Scott Med J. 2011:56(2):104-9. https://doi.org/10.1258/smj.2011.011098.

7. James HK, Chapman AW, Pattison GTR, et al. Systematic review of the current status of cadaveric simulation for surgical training. $\mathrm{Br}$ J Surg. 2019;106(13):1726-34. https://doi.org/10.1002/bjs.11325. Review

8. Scott DJ, Cendan JC, Pugh CM, et al. The changing face of surgical education: simulation as the new paradigm. J Surg Res. 2008;147: 189-93.

9. Ziv A, Small SD, Wolpe PR. Patient safety and simulation-based medical education. Med Teach. 2000;22:489-95.

10. Delpech PO, Danion J, Oriot D, et al. SimLife a new model of simulation using a pulsated revascularized and reventilated cadaver for surgical education. J Visc Surg. 2017;154(1):15-20. https://doi. org/10.1016/j.jviscsurg.2016.06.006.

11. Faure JP, Breque C, Danion J, et al. SIM Life: a new surgical simulation device using a human perfused cadaver. Surg Radiol Anat. 2017;39:211-7. https://doi.org/10.1007/s00276-016-1715-9.

12. Danion J, Oriot E, Breque C, et al. SimLife: face validation of a new dynamic simulated body model for surgical simulation. J Surg Sim. 2019;6:63-9. https://doi.org/10.1102/2051-7726.2019.0010.

13. Lo HC. The learning curve of one anastomosis gastric bypass and its impact as a preceding procedure to Roux-en Y gastric bypass: initial experience of one hundred and five consecutive cases. BMC Surg. 2020;20(1):37. https://doi.org/10.1186/s12893-020-00697-9.

14. Kolb DA. Experiential learning: experience as the source of learning and development. Englewood Cliffs: Prentice-Hall; 1984. p. xiii-256.

15. Kohn GP, Galanko JA, Overby DW, et al. High case volumes and surgical fellowships are associated with improved outcomes for bariatric surgery patients: a justification of current credentialing initiatives for practice and training. J Am Coll Surg. 2010;210(6): 909-18.

16. Altieri MS, Yang J, Yin D, et al. Presence of a fellowship improves perioperative outcomes following hepatopancreatobiliary procedures. Surg Endosc. 2017;31(7):2918-24.

17. Kim PS, Telem DA, Altieri MS, et al. Bariatric outcomes are significantly improved in hospitals with fellowship council-accredited bariatric fellowships. J Gastrointest Surg. 2015;19(4):594-7.

18. Johnston MJ, Singh P, Pucher PH, et al. Systematic review with meta-analysis of the impact of surgical fellowship training on patient outcomes. Br J Surg. 2015;102(10):1156-66.

19. Zahiri HR, Park AE, Pugh CM, et al. "See one, do one, teach one": Inadequacies of current methods to train surgeons in hernia repair. Surg Endosc. 2015;29(10):2867-72.

20. Di Saverio S, Catena F, Birindelli A, et al. "See one, do one, teach one": education and training in surgery and the correlation between surgical exposures with patients outcomes. Int J Surg. 2016;27: 126-7.

21. Krell RW, Birkmeyer NJ, Reames BN, et al. Michigan Bariatric Surgery Collaborative. Effects of resident involvement on complication rates after laparoscopic gastric bypass. J Am Coll Surg. 2014;218(2):253-60.

22. Nguyen NT, Okrainec A, Anvari M, et al. Sleeve gastrectomy telementoring: a SAGES multi-institutional quality improvement initiative. Surg Endosc. 2018;32(2):682-7.

23. Grantcharov TP, Kristiansen VB, Bendix J, et al. Randomized clinical trial of virtual reality simulation for laparoscopic skills training. Br J Surg. 2004;91(2):146-50.
24. Kundhal PS, Grantcharov TP. Psychomotor performance measured in a virtual environment correlates with technical skills in the operating room. Surg Endosc. 2009;23(3):645-9.

25. Bonrath EM, Dedy NJ, Gordon LE, et al. Comprehensive surgical coaching enhances surgical skill in the operating room: a randomized controlled trial. Ann Surg. 2015;262(2):205-12.

26. Singh P, Aggarwal R, Tahir M, et al. A randomized controlled study to evaluate the role of video-based coaching in training laparoscopic skills. Ann Surg. 2015;261(5):862-9.

27. $\mathrm{Hu}$ YY, Mazer LM, Yule SJ, et al. Complementing operating room teaching with video-based coaching. JAMA Surg. 2017;152(4): 318-25.

28. Zevin B, Dedy NJ, Bonrath EM, et al. Comprehensive simulationenhanced training curriculum for an advanced minimally invasive procedure: a randomized controlled trial. Surg Obes Relat Dis. 2017;13(5):815-24.

29. Kirkpatrick DL, Kirkpatrick JD. Evaluating training programs: the four levels - Third Edition. Berrett-Koehler Publishers, 1 janv. 2006; p. 379.

30. Gnanakumar S, Kostusiak M, Budohoski KP, et al. Effectiveness of cadaveric simulation in neurosurgical training: a review of the literature. World Neurosurg. 2018;118:88-96.

31. Ghazali A, Breque C, Léger A, et al. Testing of a complete training model for chest tube insertion in traumatic pneumothorax. Simul Healthc. 2015;10(4):239-44. https://doi.org/10.1097/SIH. 0000000000000071.

32. Kim SC, Fisher JG, Delman KA, et al. Cadaver-based simulation increases resident confidence, initial exposure to fundamental techniques, and may augment operative autonomy. J Surg Educ. 2016;73(6):e33-41. https://doi.org/10.1016/j.jsurg.2016.06.014.

33. Aydin A, Ahmed K, Khan MS, et al. The role of human cadaveric procedural simulation in urology training. J Urol. 2015;193:e273.

34. Weber EL, Leland HA, Azadgoli B, et al. Preoperative surgical rehearsal using cadaveric fresh tissue surgical simulation increases resident operative confidence. Ann Transl Med. 2017;5:302.

35. Reed AB, Crafton C, Giglia JS, et al. Back to basics: use of fresh cadavers in vascular surgery training. Surgery. 2009;146:757-63.

36. Chouari TAM, Lindsay K, Bradshaw E, et al. An enhanced fresh cadaveric model for reconstructive microsurgery training. Eur J Plast Surg. 2018;41:439-46.

37. Sharma M, Macafee D, Horgan AF. Basic laparoscopic skills training using fresh frozen cadaver: a randomized controlled trial. Am J Surg. 2013;206:23-31.

38. Pham M, Kale A, Marquez Y, et al. A perfusion-based human cadaveric model for management of carotid artery injury during endoscopic endonasal skull base surgery. J Neurol Surg B Skull Base. 2014;75:309-13.

39. Pacca P, Jhawar SS, Seclen DV, et al. 'Live cadaver' model for internal carotid artery injury simulation in endoscopic endonasal skull base surgery. Oper Neurosurg (Hagerstown). 2017;13:732-8.

40. Ciporen JN, Lucke-Wold B, Mendez G, et al. Endoscopic management of cavernous carotid surgical complications: evaluation of a simulated perfusion model. World Neurosurg. 2017;98:388-96.

41. Strickland BA, Ravina K, Kammen A, et al. The use of a novel perfusion based human cadaveric model for simulation of dural venous sinus injury and repair. Oper Neurosurg (Hagerstown). 2020:opz424. https://doi.org/10.1093/ons/opz424.

42. Tsuda S, Scott D, Doyle J, et al. Surgical skills training and simulation. Curr Probl Surg. 2009;46(4):271-370.

43. Norman G, Dore K, Grierson L. The minimal relationship between simulation fidelity and transfer of learning. Med Educ. 2012;46(7): 636-47.

44. Sarker SK, Patel B. Simulation and surgical training. Int J Clin Pract. 2007;61:2120-5.

45. Nutt J, Mehdian R, Parkin I, et al. Cadaveric surgery: a novel approach to teaching clinical anatomy. Clin Teach. 2012;9(3):148-51. 
46. Mitchell EL, Sevdalis N, Arora S, et al. A fresh cadaver laboratory to conceptualize troublesome anatomic relationships in vascular surgery. J Vasc Surg. 2012;55(4):1187-95.

47. Tseng WT, Lin YP. "Detached concern" of medical students in a cadaver dissection course: A phenomenological study. Anat Sci Educ. 2016;9(3):265-71.
48. Rizzolo LJ. Human dissection: an approach to interweaving the traditional and humanistic goals of medical education. Anat Rec. 2002;269(6):242-8.

Publisher's Note Springer Nature remains neutral with regard to jurisdictional claims in published maps and institutional affiliations. 